\title{
Ovarian cancer with peritoneal metastases has many treatment options and HIPEC is here to stay
}

\author{
Paul H. Sugarbaker ${ }^{1}$, Kurt Van der Speeten ${ }^{2}$ \\ ${ }^{1}$ MedStar Washington Hospital Center, Washington, DC, USA; ${ }^{2}$ Department of Surgery, Hospital Oost-Limburg, Genk, Belgium \\ Correspondence to: Paul H. Sugarbaker, MD. MedStar Washington Hospital Center, Washington, DC, USA. Email: Paul.Sugarbaker@outlook.com; \\ Kurt Van der Speeten. Department of Surgery, Hospital Oost-Limburg, Genk, Belgium. Email: Kurt.Vanderspeeten@zol.be. \\ Comment on: Boerner T, Zivanovic O, Chi DS. Narrative review of cytoreductive surgery and intraperitoneal chemotherapy for peritoneal metastases \\ in ovarian cancer. J Gastrointest Oncol 2021;12:S137-43. \\ Coccolini F, Fugazzola P, Montori G, et al. Intraperitoneal chemotherapy for ovarian cancer with peritoneal metastases, systematic review of the \\ literature and focused personal experience. J Gastrointest Oncol 2021;12:S144-81. \\ Spiliotis J, Prodromidou A. Narrative review of hyperthermic intraperitoneal chemotherapy (HIPEC) in patients with advanced ovarian cancer: a \\ critical reappraisal of the current evidence. J Gastrointest Oncol 2021;12:S182-8.
}

Submitted Dec 16, 2020. Accepted for publication Mar 16, 2021.

doi: 10.21037/jgo-2020-17

View this article at: http://dx.doi.org/10.21037/jgo-2020-17

Ovarian cancer is a disease whose natural history is defined by the progression of PM. Also, multiple effective treatment options are available. The surgery for ovarian cancer is of great assistance in bringing about a longterm benefit. Also, cancer chemotherapy using systemic cisplatin and systemic paclitaxel have a profound effect on survival. The chemotherapy can be used as neoadjuvant in selected patients, adjuvant systemic chemotherapy or adjuvant intraperitoneal chemotherapy. Also, biologic/ molecular treatments have been shown to be of value, most importantly bevacizumab and PARP inhibitors in selected patients.

With this plethora of possible treatment options, it is not surprising that our contributors arrive at totally different conclusions regarding management, especially the use of HIPEC. The manuscript by Boerner and coworkers at Memorial Sloan-Kettering Cancer Center (MSKCC) concludes that further randomized trials are necessary before HIPEC can be recommended (1). This negativity may result in part from their negative randomized controlled study with HIPEC-carboplatin. Unfortunately, the use of intraperitoneal carboplatin may be flawed in that data shows that carboplatin does not penetrate tissues in the same manner as does cisplatin (2). Also, its augmentation by heat is reduced.

In the contribution provided by Coccolini and his Italian colleagues, a firm recommendation for current use of HIPEC as a standard of care follows an exhaustive review of the literature (3). They advocate cisplatin and paclitaxel for treatment of PM from ovarian malignancy. The reader should remember that this is also the HIPEC most recommended for gastric cancer. Their recommendation was to use HIPEC not only for primary resection, but also for interval resection based on the Dutch RCT. Also, it was recommended for treatment of recurrent disease. Coccolini et al. does not imply that further trials are necessary to use cytoreductive surgery and HIPEC. He used the data that is currently available to make a firm recommendation NOW for patients who can safely receive treatment.

Spiliotis and Prodromidou provided the reader with a critical appraisal of HIPEC for primary resected, interval resected, and recurrent disease resected patients (4). Their research suggested that HIPEC was of benefit. However, from their evaluation of the evidence, no single HIPEC could be found superior to another. These authors request that HIPEC comparisons must be a high priority for future randomized trials.

One recommendation for ovarian cancer treatment seems to stand out over all others. This is a plea to change the goal of an "optimal cytoreduction". Our authors strongly suggest that complete removal of all visible disease is the goal for cytoreduction in ovarian malignancy. 
There is no longer a residual nodule size that qualifies as an adequate cytoreduction. Improved survival with surgical intervention is driven by those patients who had a resection of their ovarian cancer down to no visible evidence of disease. Perhaps this should not be surprising. Complete cytoreduction to no visible evidence of disease is a requirement for benefit with appendiceal malignancy, colorectal cancer and gastric cancer. Why should ovarian cancer be an exception to this rule? The goal for all cytoreductive surgery whether it is for gastrointestinal peritoneal metastases, malignant peritoneal mesothelioma, or ovarian malignancy, must be the removal of cancer to no visible evidence of disease.

\section{Acknowledgments}

Funding: None.

\section{Footnote}

Provenance and Peer Review: This article was commissioned by the editorial office, Fournal of Gastrointestinal Oncology for the focused issue "Intraperitoneal Chemotherapy for Peritoneal Metastases: HIPEC, EPIC, NIPEC, PIPAC and More". The article did not undergo external peer review.

Conflicts of Interest: Both authors have completed the ICMJE uniform disclosure form (available at http:// dx.doi.org/10.21037/jgo-2020-17). The focused issue was sponsored by the Peritoneal Surface Oncology Group International (PSOGI). Drs. PHS and KVDS served as the unpaid Guest Editors of the focused issue. The authors have no other conflicts of interest to declare.

Ethical Statement: The authors are accountable for all aspects of the work in ensuring that questions related to the accuracy or integrity of any part of the work are appropriately investigated and resolved.

Open Access Statement: This is an Open Access article distributed in accordance with the Creative Commons Attribution-NonCommercial-NoDerivs 4.0 International License (CC BY-NC-ND 4.0), which permits the noncommercial replication and distribution of the article with the strict proviso that no changes or edits are made and the original work is properly cited (including links to both the formal publication through the relevant DOI and the license). See: https://creativecommons.org/licenses/by-nc-nd/4.0/.

\section{References}

1. Boerner T, Zivanovic O, Chi DS. Narrative review of cytoreductive surgery and intraperitoneal chemotherapy for peritoneal metastases in ovarian cancer. J Gastrointest Oncol 2021;12:S137-43.

2. Los G, Verdegaal EM, Mutsaers PH, et al. Penetration of carboplatin and cisplatin into rat peritoneal tumor nodules after intraperitoneal chemotherapy. Cancer Chemother Pharmacol 1991;28:159-65.

3. Coccolini F, Fugazzola P, Montori G, et al. Intraperitoneal chemotherapy for ovarian cancer with peritoneal metastases, systematic review of the literature and focused personal experience. J Gastrointest Oncol 2021;12:S144-81.

4. Spiliotis J, Prodromidou A. Narrative review of hyperthermic intraperitoneal chemotherapy (HIPEC) in patients with advanced ovarian cancer: a critical reappraisal of the current evidence. J Gastrointest Oncol 2021;12:S182-8.
Cite this article as: Sugarbaker PH, Van der Speeten K. Ovarian cancer with peritoneal metastases has many treatment options and HIPEC is here to stay. J Gastrointest Oncol 2021;12(Suppl 1):S189-S190. doi: 10.21037/jgo-2020-17 